\title{
Uji Efektivitas Diesel Particulate Trap (Dpt) Berbahan Dasar Kuningan Dan Glasswool Terhadap Reduksi Opasitas Gas Buang Mesin Diesel Multi Silinder
}

\author{
I Made Muliatna ${ }^{1}$, Diastian Vinaya Wijanarko', Warju ${ }^{1}$ \\ Lab. Pengujian Performa Mesin Jurusan Teknik Mesin FT UNESA \\ Gedung A8 Lt.1 Kampus UNESA J1. Ketintang Surabaya 60231 \\ mademuliatna@unesa.ac.id \\ diastianwijanarko@unesa.ac.id \\ warju@unesa.ac.id
}

\begin{abstract}
Abstrak
Pertumbuhan kendaraan bermotor di Indonesia yang terus meningkat telah menyebabkan persoalan serius dalam hal peningkatan pencemaran udara. Salah satu jenis kendaraan bermotor yang membawa dampak besar terhadap pencemaran udara di Indonesia adalah kendaraan bermesin diesel. Particulate matter (PM) atau yang biasa dikenal sebagai opasitas gas buang kendaraan bermesin diesel menjadi senyawa berbahaya bila dihirup oleh manusia. Tujuan dari penelitian ini adalah untuk mengetahui pengaruh penggunaan diesel particulate trap (DPT) berbahan kuningan $(\mathrm{Cu}+\mathrm{Zn})$ dan glasswool terhadap opasitas gas buang mesin Isuzu C190. Obyek penelitian yang digunakan adalah mesin Isuzu C190. Hasil pengujian menunjukkan bahwa terjadi reduksi pada semua variasi DPT $\mathrm{Cu}+\mathrm{Zn}$. Pada DPT $\mathrm{Cu}+$ Zn $20 \mathrm{~mm}$ terjadi reduksi opasitas dengan persentase sebesar 77\% dengan nilai opasitas 17,1\%HSU. Pada DPT $\mathrm{Cu}+\mathrm{Zn} 15 \mathrm{~mm}$ terjadi reduksi opasitas dengan persentase sebesar $80 \%$ dengan nilai opasitas 15,3\%HSU. Pada DPT Cu $+\mathrm{Zn} 10 \mathrm{~mm}$ terjadi reduksi opasitas dengan persentase sebesar $82 \%$ dengan nilai opasitas $13,3 \% \mathrm{HSU}$.
\end{abstract}

\section{PENDAHULUAN}

Pertumbuhan kendaraan bermotor di Indonesia yang terus meningkat telah menyebabkan persoalan serius dalam hal peningkatan pencemaran udara. Salah satu jenis kendaraan bermotor yang membawa dampak besar terhadap pencemaran udara di Indonesia adalah kendaraan bermesin diesel. Selain populasinya besar, kendaraan bermesin diesel juga mengeluarkan jelaga yang dapat mengganggu kesehatan dan merusak lingkungan. Jelaga merupakan partikulat dengan $80,5 \%$ unsur pembentuknya adalah karbon berukutan $10 \mu \mathrm{m}$ (Nasikin, Wulan, \& Andriyanty, 2004).

Berikut adalah data perkembangan jumlah kendaran bermotor menurut jenis dan tahun 2009-2015.

Tabel 1. Pertumbuhan Jumlah Kendaran Bermotor Menurut Jenis dan Tahun 2011-2015
Kata kunci: diesel particulate trap), kuningan, glasswool, opasitas

\begin{abstract}
In Indonesia, which continues to increase has caused serious problems in terms of increasing air pollution. One type of motor vehicles that has a major impact on air pollution in Indonesia is a diesel engine vehicle. PM or commonly known as opacity exhaust diesel-engined vehicles into harmful substances when inhaled by humans. The purpose of this research is to know the effect of the use of diesel particulate trap (DPT) made of brass and glasswool to the exhaust gas of Isuzu C190. Research object used Isuzu C190 engine. The test results show the reduction in all variations of DPT $\mathrm{Cu}+\mathrm{Zn}$. In DPT Cu + Zn $20 \mathrm{~mm}$ had opacity reduction with the percentage of $77 \%$ with opacity value $17.1 \%$ HSU. In DPT Cu $+\mathrm{Zn} 15 \mathrm{~mm}$ have opacity reduction with a percentage equal to $80 \%$ with opacity value $15,3 \%$ HSU. In DPT $\mathrm{Cu}+\mathrm{Zn} 10 \mathrm{~mm}$ having opacity reduction with the percentage of $82 \%$ with opacity value $13.3 \%$ HSU.
\end{abstract}

Keywords: Diesel particulate trap, brass, glasswool, opacity

\begin{tabular}{|c|c|c|c|c|c|}
\hline $\begin{array}{c}\text { Jenis } \\
\text { Kendaraa } \\
\mathbf{n}\end{array}$ & $\mathbf{2 0 1 1}$ & $\mathbf{2 0 1 2}$ & $\mathbf{2 0 1 3}$ & $\mathbf{2 0 1 4}$ & $\mathbf{2 0 1 5}$ \\
\hline $\begin{array}{c}\text { Mobil } \\
\text { Penumpan } \\
\text { g }\end{array}$ & 9.548 .866 & $\begin{array}{r}10.432 .25 \\
9\end{array}$ & 1.484 .514 & 12.599 .03 & 13.480 .97 \\
\hline Bis & 2.254 .4062 .273 .821 & 2.286 .309 & 2.398 .84 & 2.420 .91 \\
\hline $\begin{array}{c}\text { Mobil } \\
\text { Barang }\end{array}$ & $\begin{array}{r}4.958 .7385 .286 .061 \\
\text { Sepeda } \\
\text { Motor }\end{array}$ & $\begin{array}{r}68.839 .3476 .381 .18 \\
1\end{array}$ & 54.732 .652 & 92.976 .24 & 98.881 .26 \\
\hline Jumlah & $\begin{array}{r}85.601 .3594 .373 .32 \\
1\end{array}$ & 104.118 .96 & 14.209 .26 & 21.394 .18 \\
\hline
\end{tabular}

Sesuai data pertumbuhan jumlah kendaran bermotor pada tabel 1 dalam kurun waktu 5 tahun antara tahun 20112015, jumlah kendaraan bermotor di Indonesia secara konsisten meningkat disetiap tahunnya. Setiap tahun mobil penumpang rata-rata meningkat sebesar $8 \%$, bis meningkat rata-rata sebesar $1 \%$, mobil barang meningkat rata-rata sebesar 7\%, dan sepeda motor meningkat rata-rata sebesar 9\% (Badan Pusat Statistik, 2015). 
Konsekuensi yang tidak dapat dihindari akibat pertumbuhan kendaraan bermotor yang terus meningkat adalah emisi gas buang yang dikeluarkan oleh kendaraan bermotor akan sulit untuk dikendalikan.

Sementara itu, kendaraan bermesin diesel saat ini sedang banyak diminati oleh konsumen. Alasan kuat mengapa lebih memilih mesin diesel adalah efisiensi bahan bakar yang lebih irit dan emisi $\mathrm{CO}_{2}$ yang dihasilkan lebih rendah bila dibandingkan dengan mesin bensin. Diesel juga memiliki emisi $\mathrm{NO}_{\mathrm{x}}$, namun sebagian konsumen menganggap bahwa emisi $\mathrm{CO}_{2}$ lebih berbahaya.

Mesin diesel konvensional umumnya memiliki emisi opasitas berupa jelaga yang menjadi salah satu sumber pencemaran udara baik bagi lingkungan maupun kesehatan. Opasitas biasanya ditandai oleh asap hitam pekat yang keluar dari ujung knalpot. Asap hitam kerap menyembur dari ujung knalpot apabila digas terlalu dalam dan pada saat itu konsumsi BBM cenderung lebih boros.

Emisi gas buang mesin diesel memiliki beberapa senyawa berbahaya seperti PM (Particulate Matter), CO, $\mathrm{HC}, \mathrm{NO}_{\mathrm{x}}$, dan $\mathrm{SO}_{\mathrm{x}}$. Namun, PM menjadi emisi yang dianggap paling berbahaya baik terhadap kesehatan maupun lingkungan. PM adalah partikulat berukuran $10 \mu \mathrm{m}$ dengan $80,5 \%$ unsur pembentuknya berupa karbon. Apabila PM ini terhirup oleh manusia, maka senyawa tersebut dapat mengendap dalam paru-paru dan timbul flek hitam sehingga fungsinya akan terganggu (Sugiarti, 2009).

Mengetahui dampak berbahaya yang dapat ditimbulkan oleh PM, maka perlu adanya solusi cerdas untuk mencegah opasitas sehingga dapat tereduksi secara maksimal sebelum keluar menuju lingkungan. Salah satu teknologi yang dapat diaplikasikan adalah Diesel Particulate Trap (DPT). DPT merupakan teknologi yang digunakan untuk mereduksi emisi gas buang kendaraan bermesin diesel dengan cara menyaring PM sebelum dilepaskan menuju lingkungan.

Cara kerja DPT yaitu dengan menyaring atau menjebak emisi partikulat hasil pembakaran. Agar dalam proses penyaringan emisi partikulat bisa lebih maksimal, maka dibutuhkan material tambahan berupa glasswool. Glasswool yang digunakan harus memenuhi beberapa kriteria, salah satunya adalah harus tahan terhadap suhu tinggi. Sehingga setelah melewati DPT asap hitam pekat yang umumnya keluar dari ujung knalpot mesin diesel akan tersaring dan emisi yang dikeluarkan menuju atmosfer lebih ramah terhadap lingkungan dan kesehatan manusia (Warju, 2013).

Pemasangan DPT diharuskan sedekat mungkin dengan exhaust manifold. Hal tersebut dilakukan agar temperatur yang masuk lebih dari $300^{\circ} \mathrm{C}$, sehingga dalam beberapa kondisi PM yang terjebak dapat terbakar dengan sendirinya dan tidak terjadi penyumbatan pada laluan DPT (Heywood, 1988).

Tolok ukur keberhasilan penggunaan DPT dapat dilihat dari hasil penelitian sebelumnya. Berdasarkan penelitian Samudra \& Muhaji (2013) yang berjudul "Pengaruh Penggunaan Diesel Particulate Trap Berbahan
Tembaga dan Glasswool Terhadap Opasitas Mesin Isuzu Panther 2000" disimpulkan bahwa terjadi reduksi opasitas dengan rata-rata reduksi $4,5 \%$ dari total variasi mesh. Variasi mesh DPT yang digunakan yaitu $30 \mathrm{~mm}, 40 \mathrm{~mm}$ dan $50 \mathrm{~mm}$. Pada penelitian ini terjadi reduksi opasitas pada semua variasi, terbukti DPT mesh $30 \mathrm{~mm}$ bisa mereduksi opasitas sebesar 3,5\%, DPT mesh $40 \mathrm{~mm}$ bisa mereduksi opasitas sebesar 5,3\% dan DPT mesh $50 \mathrm{~mm}$ bisa mereduksi opasitas sebesar $4,9 \%$.

Penelitian lanjutan dilakukan oleh Ariyanto \& Warju (2014) yang berjudul "Rancang Bangun Diesel Particulate Trap (DPT) Untuk Mereduksi Opasitas, Konsumsi Bahan Bakar, dan Tingkat Kebisingan Mesin Isuzu C190”. Bahan yang digunakan dalam penelitian ini adalah logam transisi berupa stainles steel dengan variasi mesh DPT yang digunakan sebesar $20 \mathrm{~mm}, 15 \mathrm{~mm}$ dan $10 \mathrm{~mm}$. Pada penelitian ini terjadi reduksi opasitas secara signifikan dengan rata-rata reduksi $80 \%$ dari total variasi mesh. Terbukti pada DPT mesh $20 \mathrm{~mm}$ terjadi reduksi opasitas sebesar 70\%, DPT mesh $15 \mathrm{~mm}$ terjadi reduksi opasitas sebesar $82 \%$ dan yang paling signifikan adalah DPT mesh $10 \mathrm{~mm}$ dengan reduksi opasitas sebesar $89 \%$.

Penelitian lanjutan juga dilakukan oleh Ariyanto \& Warju (2016) yang berjudul "Unjuk Kemampuan Diesel Particulate Trap Berbahan Tembaga dan Glasswool Terhadap Reduksi Opasitas Gas Buang". Variasi mesh DPT yang digunakan dalam penelitian ini adalah $20 \mathrm{~mm}, 15 \mathrm{~mm}$ dan $10 \mathrm{~mm}$. Pada Penelitian ini terjadi reduksi opasitas secara signifikan dengan rata-rata reduksi $81 \%$ dari total variasi mesh. Terbukti pada DPT mesh $20 \mathrm{~mm}$ terjadi reduksi opasitas sebesar $75 \%$, DPT mesh $15 \mathrm{~mm}$ terjadi reduksi opasitas sebesar $81 \%$ dan yang paling signifikan adalah DPT mesh $10 \mathrm{~mm}$ dengan reduksi opasitas sebesar $88 \%$.

Merujuk dari beberapa hasil penelitian terdahulu, dapat disimpulkan bahwa penggunaan DPT dengan desain metallic honeycomb (sarang lebah) dapat mereduksi opasitas secara signifikan. Oleh karena itu, peneliti ingin melakukan penelitian sejenis dengan menggunakan bahan yang berbeda yaitu kuningan $(\mathrm{Cu}+\mathrm{Zn})$. Objek penelitian yang digunakan adalah mesin Isuzu C190.

Rumusan masalah yang akan diteliti pada penelitian ini adalah pengaruh penggunaan diesel particulate trap (DPT) berbahan kuningan dan glasswool terhadap reduksi opasitas gas buang mesin Isuzu C190?

\section{Particulate Matter (PM)}

\section{KAJIAN PUSTAKA}

Particulate meter (PM) merupakan campuran kompleks zat organik dan inorganik. PM dapat menimbulkan masalah kesehatan manusia. Apabila terhirup PM dapat mencapai sistem respirasi dan paru-paru sehingga fungsinya dapat terganggu (Agustin, 2012).

Menurut Zannaria, Roosmini, \& Santoso (2009), ukuran partikulat yang dapat masuk ke dalam sistem respirasi manusia berukuran kurang dari $10 \mu \mathrm{m}$ dengan spesifikasi: 
- Ukuran 5 - $10 \mu \mathrm{m}$ akan mudah tersaring secara fisik oleh rambut-rambut halus dalam rongga hidung.

- Ukuran 2 - $5 \mu \mathrm{m}$ akan terendapkan di alveoli.

- Ukuran $<2 \mu \mathrm{m}$ akan mudah masuk ke dalam saluran respirasi dan akan mudah keluar kembali bersama udara ekspirasi.

Particulate matter (PM) adalah campuran partikel padat dan butiran cairan yang ditemukan di udara. PM merupakan polutan yang dihasilkan oleh emisi gas buang pada mesin diesel. PM menjadi polutan yang paling banyak menimbulkan dampak kesehatan dibandingkan polutan lainnya. Jika terhirup, PM dapat mengendap dalam sel paruparu sehingga fungsinya terganggu dan menimbulkan flek hitam pada paru-paru.

\section{Diesel Particulate Trap (DPT)}

Diesel particulate trap (DPT) biasa disebut dengan diesel particulate filter (DPF). Teknologi ini digunakan untuk menyaring asap hitam (smog) yang keluar dari knalpot motor diesel. Telah kita ketahui bahwa mesin diesel konvensional cenderung menghasilkan opasitas (kepekatan asap) yang tinggi jika dibandingkan dengan mesin diesel modern (berteknologi common-rail system).

Berikut ini yang menunjukkan penampang dan posisi penjebak partikulat pada knalpot mesin diesel.



Gambar 1. Penampang penjebak partikulat Sumber: Heywood (1988)

Dalam proses penyaringan PM ditahan oleh glasswool, sehingga yang keluar menuju atmosfir berupa asap putih dengan cara melewati pori-pori yang terdapat pada DPT. Untuk mengetahui seberapa besar kemampuan DPT dalam menyaring PM, maka perlu dilakukan pengujian opasitas gas buang.

Prinsip pengujian opasitas gas buang pada mesin diesel dapat dilihat pada gambar 2 .

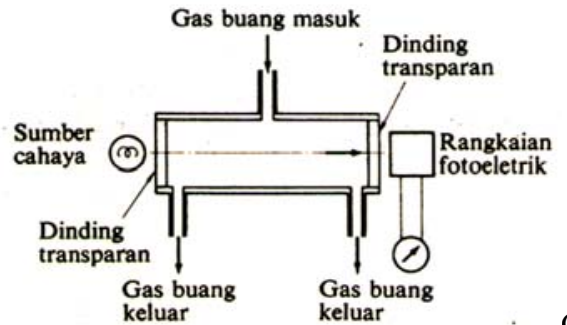

Prinsip pengujian opasitas Sumber: Arismunandar

(1983:52)

\section{Jenis Penelitian}

\section{METODE PENELITIAN}

Jenis penelitian yang digunakan dalam penelitian ini adalah penelitian eksperimen (experimental research). Tujuan dari penelitian ini yaitu untuk membandingkan seberapa besar reduksi opasitas gas buang sebelum dan sesudah pemasangan diesel particulate trap berbahan kuningan dan glasswool di saluran knalpot.

\section{Obyek Penelitian}

Adapun objek penelitian yang digunakan dalam penelitian ini adalah mesin Isuzu C190.

\section{Variabel Penelitian}

Variabel penelitian merupakan suatu atribut obyek yang mempunyai variasi antara satu obyek dengan obyek yang lainnya (Sugiyono, 2006).

Variabel yang termasuk dalam peneltian ini, yaitu:

1. Variabel bebas

Variabel bebas dalam penelitian ini adalah knalpot standar dan knalpot eksperimen yang telah dimodifikasi dengan DPT berbahan kuningan dan glasswool.

2. Variabel terikat

Variabel terikat dalam penelitian ini adalah kepekatan asap (opasitas) gas buang yang dihasilkan dari proses pembakaran mesin diesel.

3. Variabel kontrol

Variabel kontrol dalam penelitian ini adalah putaran mesin, bahan bakar solar, dan temperatur oli mesin.

\section{Instrumen Penelitian}

Instrumen penelitian merupakan alat ukur yang digunakan sebagai komponen utama dalam proses pengujian untuk mendapatkan data hasil penelitian. 


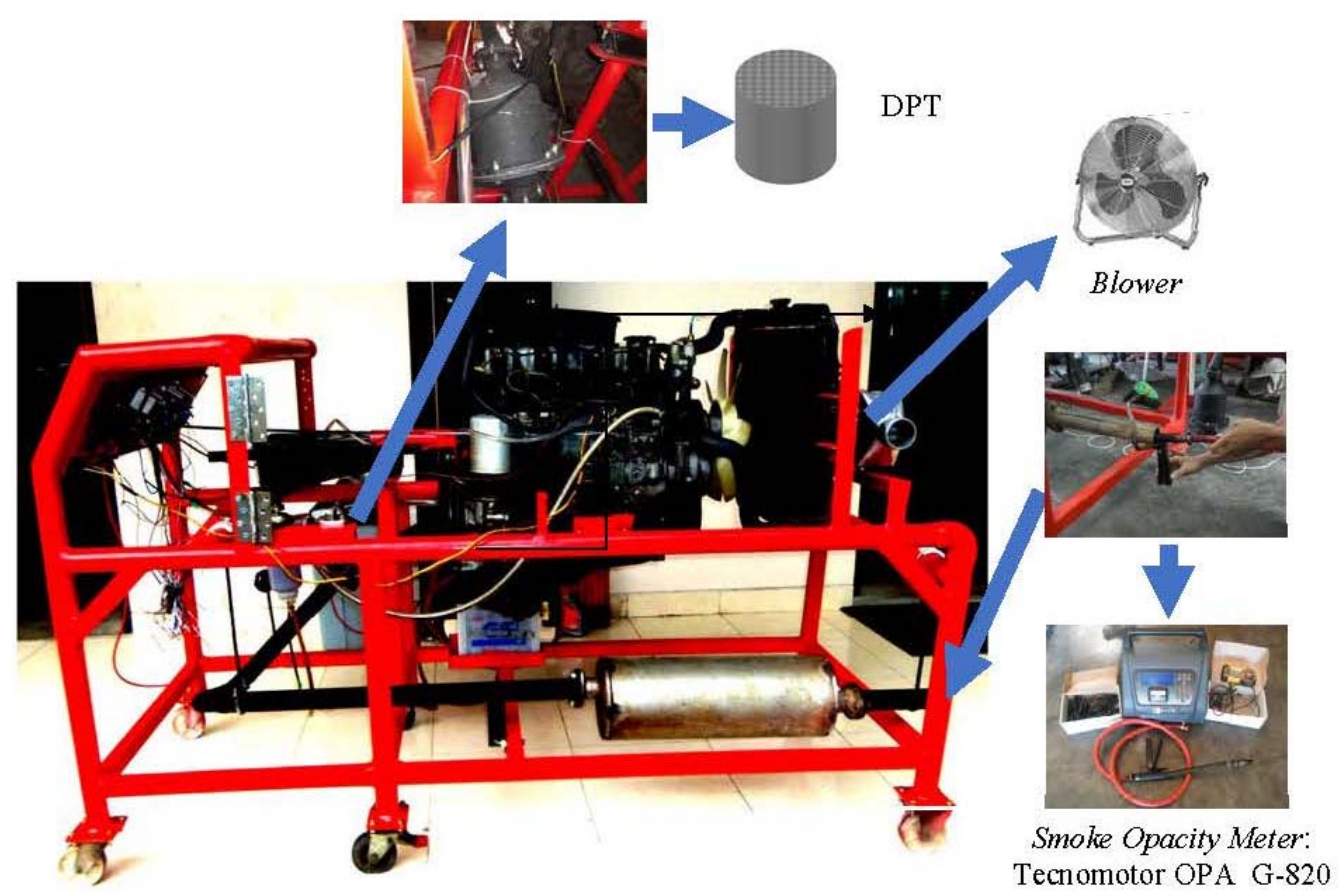

Gambar 3. Skema instrumen penelitian

\section{Metode Pengujian}

Agar mendapatkan data penelitian yang akurat, metode pengujian harus sesuai dengan standar yang berlaku. Pengujian opasitas gas buang kendaraan bermesin diesel dilakukan berdasarkan standar SNI 09-7118.2-2005, yaitu dengan putaran mesin yang diakselerasi tanpa beban (free running acceleration) yang mengacu pada SAE J1667 (snap acceleration test procedure). Alat ukur yang digunakan adalah smoke opacity meter Tecnomotor OPA-820.

\section{Teknik Analisis Data}

Analisis data menggunakan metode deskriptif, dengan mendeskripsikan secara sistematis fakta sesuai dari hasil pengujian (Nazir, 2005:54). Data hasil pengujian dimasukkan ke dalam tabel dan ditampilkan dalam bentuk diagram batang untuk opasitas.

Kemudian data hasil penelitian dideskripsikan dengan kalimat yang sederhana agar mudah dipahami. Hal ini bertujuan agar mendapatkan gambaran terhadap fenomena yang terjadi sebelum dan setelah menerapkan diesel particulate trap (DPT) pada diesel engine stand Isuzu C190.

\section{HASIL DAN PEMBAHASAN}

\section{Hasil}

Tabel 2. Data Hasil Pengujian Opasitas Gas Buang

\begin{tabular}{|c|c|c|c|}
\hline Knalpot & $\begin{array}{c}\text { Tahap } \\
\text { Pengujian }\end{array}$ & $\begin{array}{c}\text { Nilai } \\
\text { Opasitas } \\
\text { (\%HSU) }\end{array}$ & $\begin{array}{c}\text { Nilai Rata- } \\
\text { Rata } \\
\text { Opasitas } \\
\text { (\%HSU) }\end{array}$ \\
\hline \multirow{3}{*}{ Standar } & 1 & 76,6 & \multirow{3}{*}{75,5} \\
\hline & 2 & 75,3 & \\
\hline & 3 & 74,6 & \\
\hline \multirow{3}{*}{$\begin{array}{c}\text { DPT } \\
\mathrm{Cu}+\mathrm{Zn} \\
20 \mathrm{~mm}\end{array}$} & 1 & 17 & \multirow{3}{*}{17,1} \\
\hline & 2 & 16,3 & \\
\hline & 3 & 18 & \\
\hline \multirow{3}{*}{$\begin{array}{c}\text { DPT } \\
\mathrm{Cu}+\mathrm{Zn} \\
15 \mathrm{~mm}\end{array}$} & 1 & 16 & \multirow{3}{*}{15,3} \\
\hline & 2 & 16 & \\
\hline & 3 & 14 & \\
\hline \multirow{3}{*}{$\begin{array}{c}\text { DPT } \\
\mathrm{Cu}+\mathrm{Zn} \\
10 \mathrm{MM}\end{array}$} & 1 & 13 & \multirow{3}{*}{13,3} \\
\hline & 2 & 13,2 & \\
\hline & 3 & 13,8 & \\
\hline
\end{tabular}

\section{Pembahasan}

Berdasarkan hasil pengujian yang telah dilakukan, penggunaan DPT berbahan kuningan dan glasswool terbukti dapat mereduksi opasitas gas buang pada mesin Isuzu C190. Persentase hasil reduksi dapat dilihat pada 3. 
Tabel 3. Persentase Reduksi Opasitas Gas Buang

\begin{tabular}{|c|c|c|}
\hline Knalpot & $\begin{array}{c}\text { Opasitas } \\
(\mathbf{\% H S U})\end{array}$ & $\begin{array}{c}\text { Reduksi } \\
\text { Opasitas } \\
(\%)\end{array}$ \\
\hline Standar & 75,5 & \\
\hline $\begin{array}{c}\mathrm{DPT} \\
\mathrm{Cu}+\mathrm{Zn} 20 \\
\mathrm{~mm}\end{array}$ & 17,1 & $77 \%$ \\
\hline $\mathrm{DPT}$ & 15,3 & $80 \%$ \\
\hline
\end{tabular}

\begin{tabular}{|c|c|c|}
\hline Knalpot & $\begin{array}{c}\text { Opasitas } \\
(\% \text { \%SU) }\end{array}$ & $\begin{array}{c}\text { Reduksi } \\
\text { Opasitas } \\
(\%)\end{array}$ \\
\hline $\begin{array}{c}\mathrm{Cu}+\mathrm{Zn} 15 \\
\mathrm{~mm}\end{array}$ & & \\
\hline $\begin{array}{c}\mathrm{DPT} \\
\mathrm{Cu}+\mathrm{Zn} 10 \\
\mathrm{MM}\end{array}$ & 13,3 & $82 \%$ \\
\hline
\end{tabular}

Dari data tabel 3 apabila ditampilkan ke dalam bentuk diagram batang dan grafik untuk opasitas, maka akan terlihat seperti pada gambar 4 dan 5 .

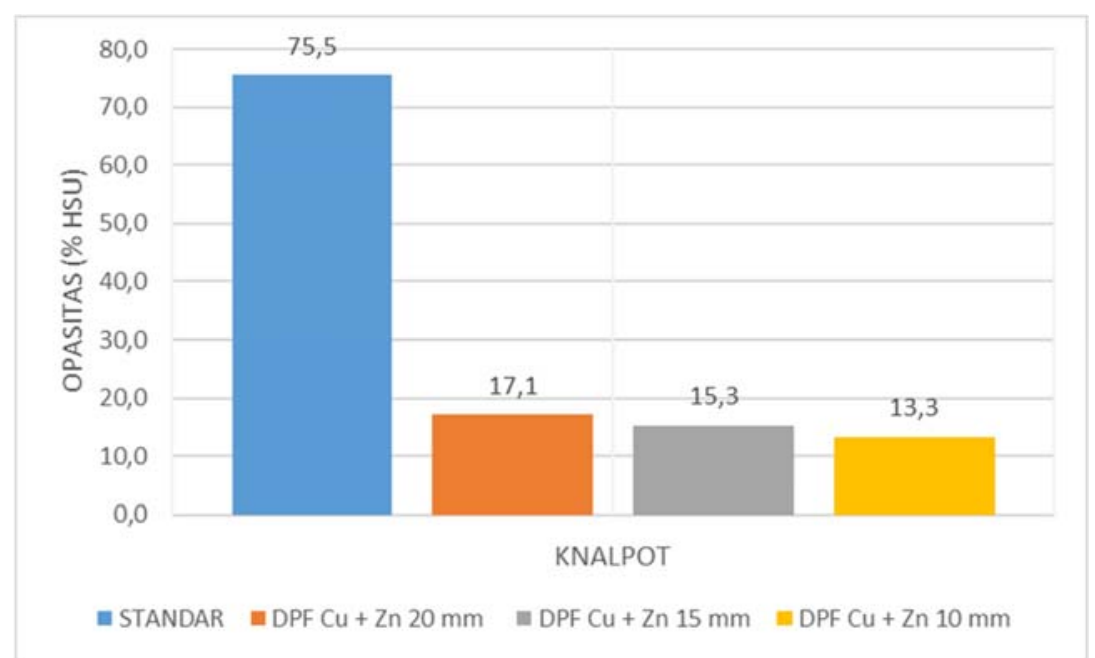

Gambar 4. Diagram perbandingan hasil pengujian opasitas knalpot standar dan eksperimen

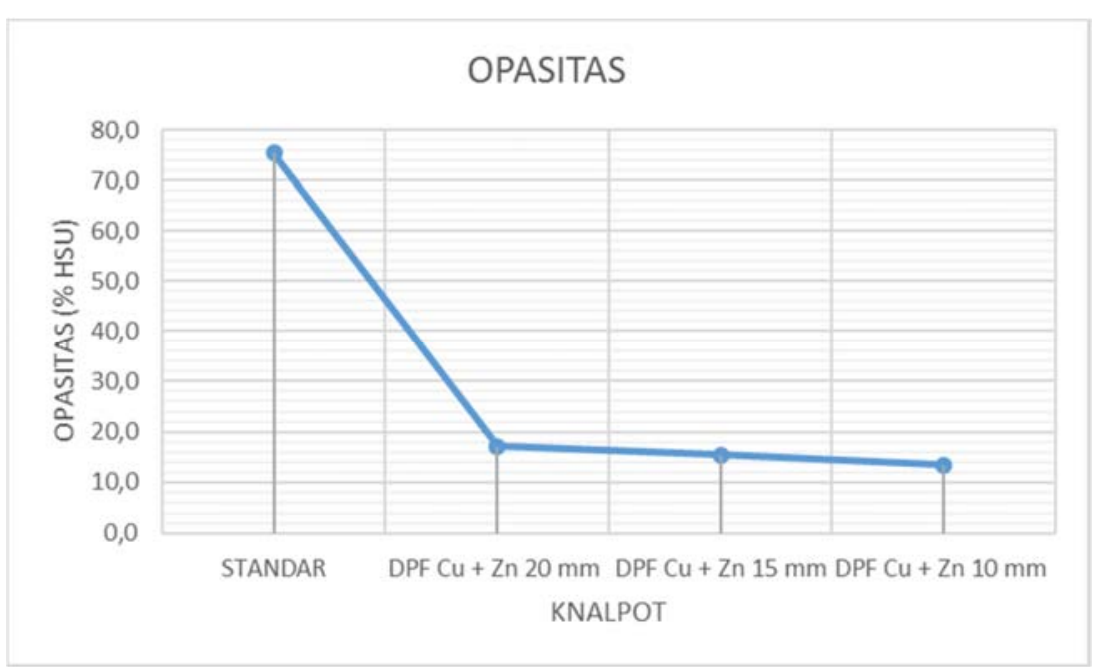

Gambar 5. Grafik perbandingan hasil pengujian opasitas knalpot standar dan eksperimen

Berdasarkan data pada tabel 2 dan 3 serta gambar 4 dan 5 dapat dinyatakan bahwa penggunaan DPT $\mathrm{Cu}+\mathrm{Zn}$ dan glasswool dapat menurunkan opasitas gas buang secara signifikan. Reduksi terbesar terdapat pada DPT $\mathrm{Cu}+\mathrm{Zn}$ dengan variasi mesh $10 \mathrm{~mm}$.
Untuk lebih jelasnya tentang hasil pengujian yang telah dilakukan, maka akan dibahas sesuai analisis di bawah ini.

\section{Knalpot Standar}


Berdasarkan Peraturan Menteri Negara Lingkungan Hidup Nomor 5 tahun 2006, batasan opasitas maksimum kendaraan penyalaan kompresi sebesar 70 \%HSU. Berdasarkan data hasil pengujian pada knalpot standar Isuzu C190, didapatkan data opasitas sebesar 75,5 \%HSU (hartridge smoke unit). Apabila dibandingkan besaran opasitas knalpot standar dengan Peraturan Menteri Negara Lingkungan Hidup Nomor 5 tahun 2006, maka dapat dinyatakan knalpot standar belum lulus uji emisi. Hal tersebut terjadi karena tidak terdapat teknologi yang berfungsi sebagai penyaring material PM.

\section{DPT Cu + Zn 20 mm}

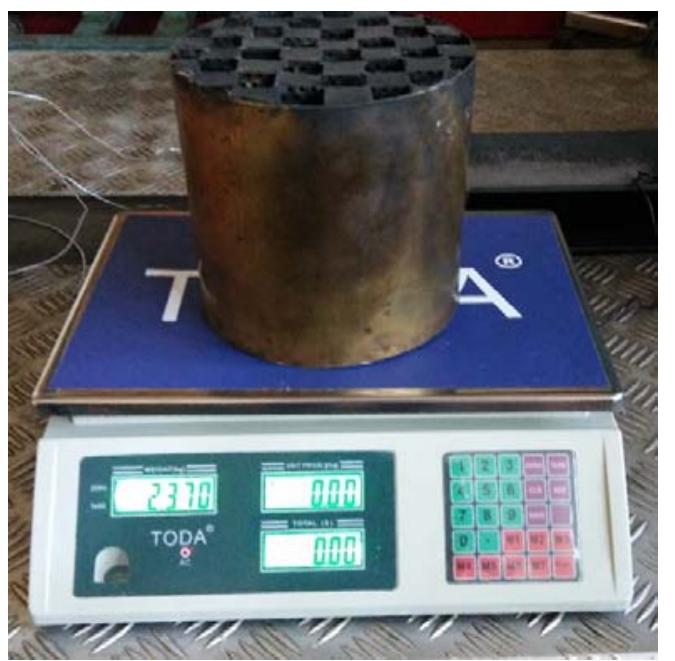

(a)
Berdasarkan hasil pengujian, didapatkan data bahwa dengan menggunakan DPT $\mathrm{Cu}+\mathrm{Zn} 20 \mathrm{~mm}$ terjadi reduksi opasitas sebesar $77 \%$ dengan nilai opasitas sebesar 17,1 $\%$ HSU. Apabila hasil reduksi opasitas dibandingkan dengan Peraturan Menteri Negara Lingkungan Hidup Nomor 5 tahun 2006, maka dapat dinyatakan bahwa penggunaan DPT $\mathrm{Cu}+\mathrm{Zn} 20 \mathrm{~mm}$ sebagai pereduksi opasitas gas buang masuk pada kategori lulus uji emisi.

Pada DPT $\mathrm{Cu}+\mathrm{Zn} 20 \mathrm{~mm}$ ini terdapat glasswool sebesar 100 gr yang berfungsi sebagai material penjebak (penyaring) PM (particulate trap) hasil dari proses pembakaran. Sebagai bukti bahwa telah terjadi reduksi opasitas pada DPT $\mathrm{Cu}+\mathrm{Zn} 20 \mathrm{~mm}$, dapat dilihat pada gambar 6.

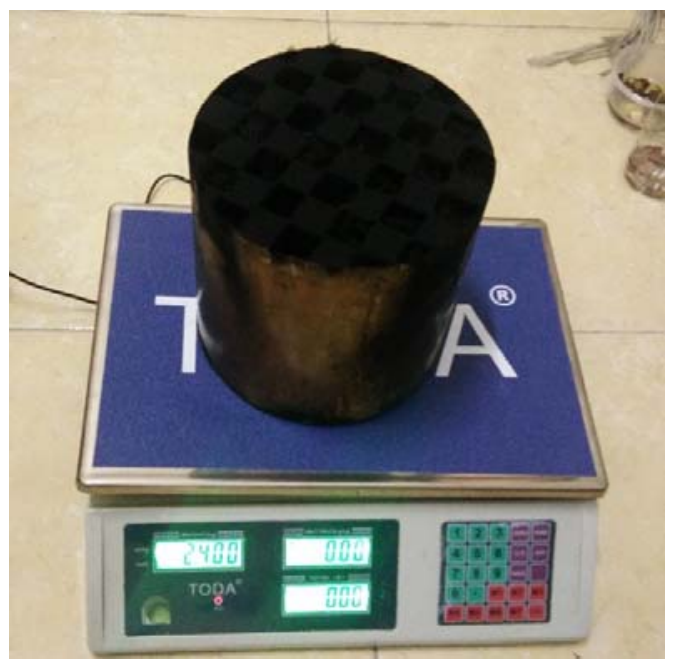

(b)

Gambar 6. (a) pada DPT Cu + Zn 20 mm sebelum pengujian, (b) pada DPT Cu + Zn 20 mm setelah pengujian

Sebelum melakukan pengujian terlebih dahulu dilakukan proses penimbangan. Hal tersebut bertujuan agar kita dapat mengetahui berat DPT Cu + Zn 20 mm sebelum dan sesudah melakukan pengujian. Hasilnya sebelum melakukan pengujian berat DPT $\mathrm{Cu}+\mathrm{Zn} 20 \mathrm{~mm}$ sebesar $2,370 \mathrm{~kg}$ dan setelah dilakukan pengujian beratnya bertambah 30 gr menjadi 2,400 kg. Mengetahui hal tersebut, maka dapat dinyatakan bahwa terdapat 30 gr PM yang dapat tersaring oleh material glasswool yang terpasang pada DPT $\mathrm{Cu}+\mathrm{Zn} 20 \mathrm{~mm}$.

\section{DPT Cu + Zn 15 mm}

Berdasarkan hasil pengujian, didapatkan data bahwa dengan menggunakan DPT $\mathrm{Cu}+\mathrm{Zn} 15 \mathrm{~mm}$ terjadi reduksi opasitas sebesar $80 \%$ dengan nilai opasitas sebesar 15,3 $\%$ HSU. Apabila hasil reduksi opasitas dibandingkan dengan Peraturan Menteri Negara Lingkungan Hidup Nomor 5 tahun 2006, maka dapat dinyatakan bahwa penggunaan DPT $\mathrm{Cu}+\mathrm{Zn} 15 \mathrm{~mm}$ sebagai pereduksi opasitas gas buang masuk pada kategori lulus uji emisi.

Pada DPT $\mathrm{Cu}+\mathrm{Zn} 15 \mathrm{~mm}$ ini terdapat glasswool sebesar 100 gr yang berfungsi sebagai material penjebak (penyaring) PM (particulate trap) hasil dari proses pembakaran. Sebagai bukti bahwa telah terjadi reduksi opasitas pada DPT $\mathrm{Cu}+\mathrm{Zn} 15 \mathrm{~mm}$, dapat dilihat pada gambar 7. 




(a)

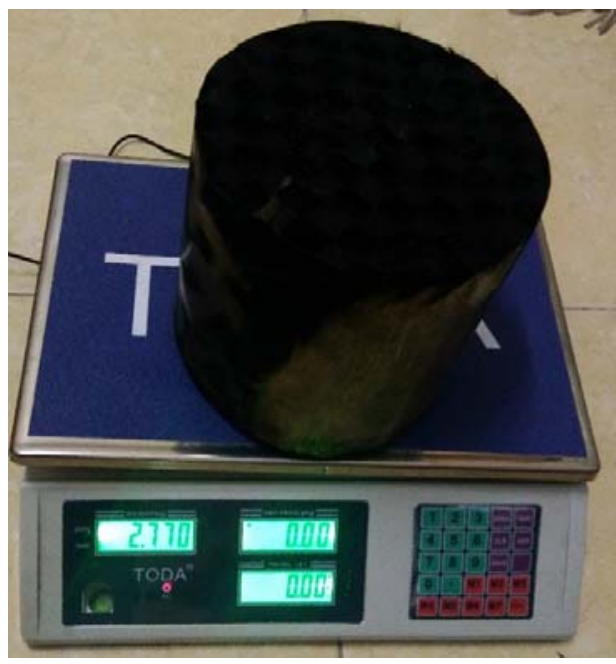

(b)

Gambar 7. (a) DPT $\mathrm{Cu}+\mathrm{Zn} 15 \mathrm{~mm}$ sebelum pengujian, (b) DPT $\mathrm{Cu}+\mathrm{Zn} 15 \mathrm{~mm}$ setelah pengujian

Sebelum melakukan pengujian terlebih dahulu dilakukan proses penimbangan. Hal tersebut bertujuan agar kita dapat mengetahui berat DPT $\mathrm{Cu}+\mathrm{Zn} 15 \mathrm{~mm}$ sebelum dan sesudah melakukan pengujian. Hasilnya sebelum melakukan pengujian berat DPT $\mathrm{Cu}+\mathrm{Zn} 15 \mathrm{~mm}$ sebesar $2,730 \mathrm{~kg}$ dan setelah dilakukan pengujian beratnya bertambah 40 gr menjadi 2,770 kg. Mengetahui hal tersebut, maka dapat dinyatakan bahwa terdapat 40 gr PM yang dapat tersaring oleh material glasswool yang terpasang pada DPT $\mathrm{Cu}+\mathrm{Zn} 15 \mathrm{~mm}$.

\section{DPT Cu + Zn 10 mm}

Berdasarkan hasil pengujian, didapatkan data bahwa dengan menggunakan DPT $\mathrm{Cu}+\mathrm{Zn} 10 \mathrm{~mm}$ terjadi reduksi

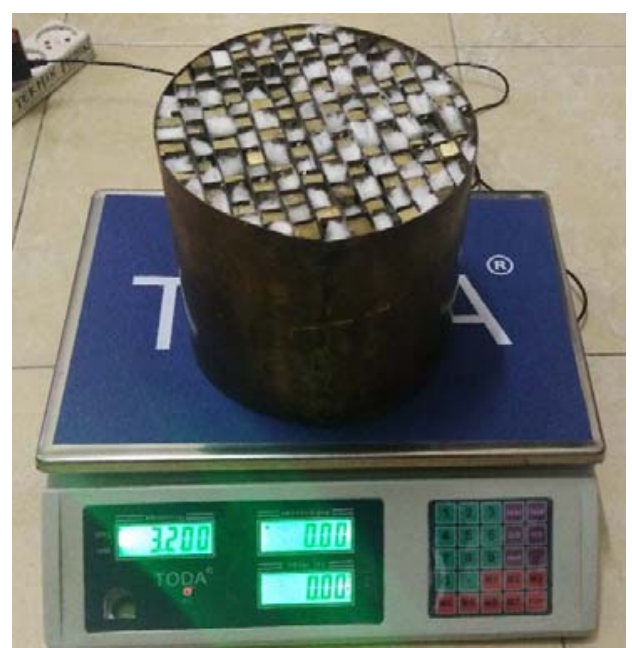

(a) opasitas yang signifikan sebesar $82 \%$ dengan nilai opasitas sebesar 13,3 \%HSU. Apabila hasil reduksi opasitas dibandingkan dengan Peraturan Menteri Negara Lingkungan Hidup Nomor 5 tahun 2006, maka dapat dinyatakan bahwa penggunaan DPT Cu $+\mathrm{Zn} 10 \mathrm{~mm}$ sebagai pereduksi opasitas gas buang masuk pada kategori lulus uji emisi.

Pada DPT Cu $+\mathrm{Zn} 10 \mathrm{~mm}$ ini terdapat glasswool sebesar 100 gr yang berfungsi sebagai material penjebak (penyaring) PM (particulate trap) hasil dari proses pembakaran. Sebagai bukti bahwa telah terjadi reduksi opasitas secara signifikan setelah menggunakan DPT Cu + Zn $10 \mathrm{~mm}$, dapat dilihat pada gambar 8 .

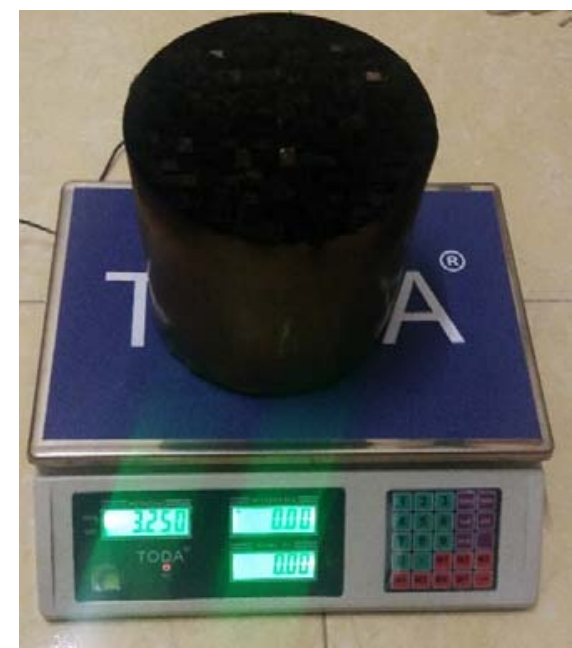

(b)

Gambar 8. (a) DPT Cu $+\mathrm{Zn} 10 \mathrm{~mm}$ sebelum pengujian, (b) DPT Cu $10+\mathrm{Zn} \mathrm{mm}$ setelah pengujian 
Sebelum melakukan pengujian terlebih dahulu dilakukan proses penimbangan. Hal tersebut bertujuan agar kita dapat mengetahui berat DPT $\mathrm{Cu}+\mathrm{Zn} 10 \mathrm{~mm}$ sebelum dan sesudah melakukan pengujian. Hasilnya sebelum melakukan pengujian berat DPT $\mathrm{Cu}+\mathrm{Zn} 10 \mathrm{~mm}$ sebesar $3,200 \mathrm{~kg}$ dan setelah dilakukan pengujian beratnya bertambah 50 gr menjadi 3,250 kg. Mengetahui hal tersebut, maka dapat dinyatakan bahwa terdapat $50 \mathrm{gr}$ PM yang dapat tersaring oleh material glasswool yang terpasang pada DPT $\mathrm{Cu}+\mathrm{Zn} 10 \mathrm{~mm}$.

Apabila dilakukan perbandingan antara DPT Cu $+\mathrm{Zn}$ $20 \mathrm{~mm}$ dibandingkan dengan DPT $\mathrm{Cu}+\mathrm{Zn} 15 \mathrm{~mm}$ dan DPT $\mathrm{Cu}+\mathrm{Zn} 10$ mm, maka sudah jelas bahwa DPT Cu + Zn 10 $\mathrm{mm}$ menjadi teknologi penyaring material PM terbaik. Hal ini terbukti berdasarkan hasil penyaringan material PM yang dilakukan DPT $\mathrm{Cu}+\mathrm{Zn} 20 \mathrm{~mm}$ hanya sebesar 30 gr dan DPT Cu + Zn $15 \mathrm{~mm}$ sebesar 40 gr, sedangkan DPT $10 \mathrm{~mm}$ dapat menyaring material PM sebesar 50 gr. Sehingga dapat ditarik kesimpulan bahwa variasi mesh akan sangat mempengaruhi terhadap hasil penyaringan.

Untuk mengetahui apakah dengan menggunakan DPT $\mathrm{Cu}+\mathrm{Zn}$ pada Isuzu C190 memenuhi kriteria standar opasitas maksimum yang diizinkan sesuai dengan Peraturan Menteri Negara Lingkungan Hidup No 5 Tahun 2006 tentang Ambang Batas Emisi Gas Buang Kendaraan Bermotor Lama, maka perlu dilakukan perbandingan antara penggunaan knalpot standar dan penggunaan DPT $\mathrm{Cu}+\mathrm{Zn}$ yang dapat dilihat pada tabel 4 berikut ini.

Tabel 4. Perbandingan Hasil Opasitas Gas Buang Terhadap Peraturan Pemerintah

\begin{tabular}{|c|c|c|c|}
\hline Knalpot & $\begin{array}{c}\text { Opasitas } \\
(\% \text { AmS })\end{array}$ & $\begin{array}{c}\text { Ambang } \\
\text { Batas } \\
\text { (\%HSU) }\end{array}$ & Keterangan \\
\hline Standar & 75,5 & 70 & Tidak Lulus Uji Emisi \\
\hline $\begin{array}{c}\text { DPT Cu }+\mathrm{Zn} \\
20 \mathrm{~mm}\end{array}$ & 17,1 & 70 & Lulus Uji Emisi \\
\hline $\begin{array}{c}\text { DPT } \mathrm{Cu}+\mathrm{Zn} \\
15 \mathrm{~mm}\end{array}$ & 15,3 & 70 & Lulus Uji Emisi \\
\hline $\begin{array}{c}\text { DPT Cu }+\mathrm{Zn} \\
10 \mathrm{~mm}\end{array}$ & 13,3 & 70 & Lulus Uji Emisi \\
\hline
\end{tabular}

\section{SIMPULAN}

Berdasarkan data hasil pengujian, analisis data, dan pembahasan yang telah dilakukan tentang penggunaan DPT berbahan dasar kuningan $(\mathrm{Cu}+\mathrm{Zn})$ dan glasswool dengan desain metallic honeycomb, dapat disimpulkan bahwa:

1. Pada DPT Cu + Zn $20 \mathrm{~mm}, 15 \mathrm{~mm}$, dan $10 \mathrm{~mm}$ terjadi reduksi opasitas rata-rata sebesar $77-82 \%$ jika dibandingkan dengan knalpot standar.

2. DPT $\mathrm{Cu}+\mathrm{Zn} 20 \mathrm{~mm}$ dapat mereduksi opasitas mesin Isuzu C190 dengan persentase sebesar 77\% dengan nilai opasitas $17,1 \% \mathrm{HSU}$.

3. DPT $\mathrm{Cu}+\mathrm{Zn} 15 \mathrm{~mm}$ dapat mereduksi opasitas mesin Isuzu C190 dengan persentase sebesar 80\% dengan nilai opasitas $15,3 \% \mathrm{HSU}$.

4. DPT $\mathrm{Cu}+\mathrm{Zn} 10 \mathrm{~mm}$ dapat mereduksi opasitas mesin Isuzu C190 dengan persentase sebesar 82\% dengan nilai opasitas $13,3 \% \mathrm{HSU}$.

\section{Ucapan Terima Kasih}

Penelitian ini dibiayai oleh Direktorat Penelitian dan Pengabdian Kepada Masyarakat (DRPM) Ristekdikti melalui skim Penelitian Produk Terapan (PPT) tahun anggaran 2017. Terimakasih kami sampaikan kepada Jurusan Teknik Mesin dan Laboratorium Pengujian Performa Mesin Jurusan Teknik Mesin FT UNESA yang telah memberikan dukungan dan fasilitas selama proses penelitian.

\section{DAFTAR PUSTAKA}

Agustin, S. (2012). Hubungan Particulate Matter (PM10) dan Nitrogen Dioksida $\left(\mathrm{NO}_{2}\right)$ dengan Jumlah Asma di Jakarta Pusat Tahun 2007-2011. Jakarta: Universitas Indonesia.

Ariyanto, S. R., \& Warju. (2014). Rancang bangun diesel particulate trap (DPT) untuk mereduksi opasitas, konsumsi bahan bakar, dan tingkat kebisingan mesin Isuzu C190. Jurnal Rekayasa Mesin, 1(3), 19-28.

Ariyanto, S. R., \& Warju. (2016). Unjuk kemampuan diesel particulate trap berbahan tembaga dan glasswool terhadap reduksi opasitas gas buang. Jurnal Otopro, 11(2), 187-195.

Badan Pusat Statistik. (2015). Perkembangan Jumlah Kendaraan Bermotor Menurut Jenis, 1949-2015. Jakarta: BPS.

Heywood, J. B. (1988). Internal Combustion Engine Fundementals. McGrawHill series in Mechanical Engineering (Vol. 21). https://doi.org/10987654.

Nazir, M. 2005. Metode Penelitian. Bogor: Penerbit Ghalia Indonesia.

Nasikin, M., Wulan, P. P. D. K., \& Andriyanty, V. (2004). Pemodelan dan simulasi katalitik konverter packed bed untuk mengoksidasi jelaga pada gas buang kendaraan bermesin diesel. Makara Teknologi, 8(3), 69-76.

Peraturan Menteri Negara Lingkungan Hidup No 05 Tahun 2006 Tentang Ambang Batas Emisi Gas Buang Kendaraan Bermotor Lama. Jakarta: Kementerian Lingkungan Hidup.

SAE J1667. (1996). Surface Vehicle Recommended Practice. In Snap-Acceleration Smoke Test Procedure for Heavy Duty Diesel Powered Vehicles.

Samudra, A., \& Muhaji. (2013). Pengaruh penggunaan diesel particulate trap berbahan tembaga dan glasswool terhadap opasitas mesin Isuzu Panther 2000. Jurnal Teknik Mesin, 
$1(3), 23-31$.

SNI 09-7118.2. (2005). Emisi gas buang - Sumber bergerak Bagian 2: Cara uji kendaraan bermotor kategori $M, N$, dan $O$ berpenggerak penyalaan kompresi pada kondisi akselerasi bebas.

Sugiarti. (2009). Gas pencemar udara dan pengaruhnya bagi kesehatan manusia. Jurnal Chemical, 10(1), 50-58.

Sugiyono. (2006). Metode Penelitian Kuantitatif, Kualitatif dan $R$ $\& D$. Bandung: Alfabeta.

Warju. (2013). Teknologi Reduksi Emisi Gas Buang Kendaraan Bermotor. Surabaya: Unesa University Press.

Zannaria, N. D., Roosmini, D., \& Santoso, M. (2009). Karakteristik kimia paparan partikulat terespirasi. Jurnal Sains dan Teknologi Nuklir Indonesia, IX(Februari 2009), 37-50. 